Supplement of The Cryosphere, 14, 833-840, 2020 https://doi.org/10.5194/tc-14-833-2020-supplement (C) Author(s) 2020. This work is distributed under the Creative Commons Attribution 4.0 License.

(c) (1)

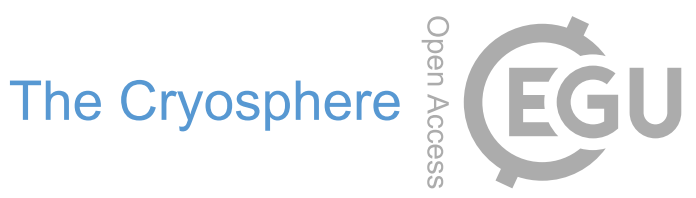

Supplement of

\title{
Brief communication: On calculating the sea-level contribution in marine ice-sheet models
}

Heiko Goelzer et al.

Correspondence to: Heiko Goelzer (h.goelzer@uu.nl)

The copyright of individual parts of the supplement might differ from the CC BY 4.0 License. 

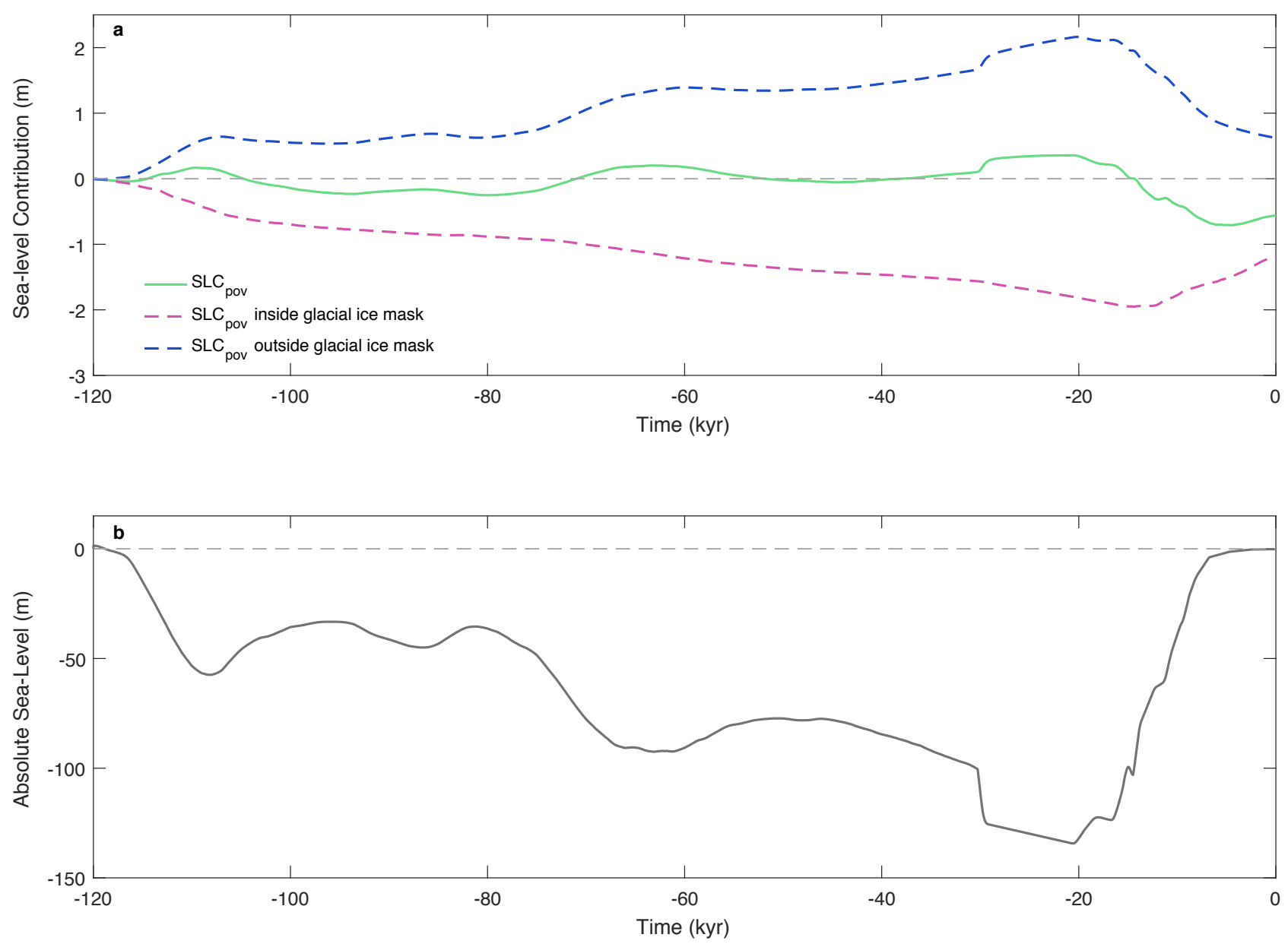

Figure S1 (a) Sea-level contribution from an Antarctic ice-sheet model simulation calculated from changes in potential ocean volume $\left(S L C_{\text {pov }}\right)$ for the last glacial cycle under external sea-level forcing. (b) Sea-level reconstruction (Bintanja et al., 2008; Lambeck et al., 2014) used as external sea-level forcing. $S L C_{\text {pov }}$ shows a combination of bedrock adjustment under the (mostly 5 growing) ice sheet (negative signal) and the isostatic response of the ocean floor to externally-forced decreasing water loading (positive signal). These two contributions can be estimated by fixing two distinct calculation domains for $S L C_{\text {pov }}$ : 1) inside the glacial ice mask (calculated at $20 \mathrm{kyr}$ BP) where the signal of isostatic adjustment under the growing ice sheet is dominant, and 2) outside the glacial ice mask where the effect of rising ocean floor is dominant. These estimates are represented in (a). Both signals are of similar amplitude, but $S L C_{\text {pov }}$ is dominated by ocean floor movements after periods of rapid sea-level forcing change. 